\title{
Attraktive Tarife bei den Personalversicherungen
}

\author{
Profitieren Sie und Ihr Personal jetzt von günstigeren Prämien
}

\section{Versicherungslösungen für Ihr Personal}

Als Arbeitgeber sind Sie verpflichtet, Ihr Personal gegen die Risiken Tod und Erwerbsunfähigkeit zu versichern. Das Schweizer Sozialversicherungssystem basiert auf dem 3-Säulen-Konzept, wobei die Abstimmung dieser drei Säulen sehr komplex ist. Die FMH Insurance Services Berater helfen Ihnen dabei, die für Sie und Ihr Personal optimalen Lösungen zu finden:

- UVG - Obligatorische Unfallversicherung

- KTG - Kollektive Krankentaggeldversicherung

- BVG - Berufliche Vorsorge (2. Säule)

\section{Speziallösungen nur für Ärzte}

Da der Anbieter der verschiedenen Versicherungslösungen frei ausgewählt werden kann, gibt es teilweise grosse Unterschiede in den Prämiensätzen. Wir haben für Sie die zahlreichen Angebote überprüft und konnten mit dem Versicherer KPT einen attraktiven Rahmenvertrag für die UVG- und Krankentaggeldversicherung aushandeln. Im Bereich der beruflichen Vorsorge BVG bieten wir Ihnen die verschiedenen Lösungen der standeseigenen Pensionskassen an, die sich auf die Bedürfnisse der Ärzteschaft spezialisiert haben.

\section{Vergleichen lohnt sich}

Testen Sie unser Angebot und vergleichen Sie Ihre bestehenden Verträge mit unserem Angebot, damit Sie und Ihre Mitarbeiterinnen und Mitarbeiter von tieferen Prämien profitieren können.

\section{Antworttalon}

Vorname / Name

Adresse

PLZ / Ort

Geburtsdatum

Telefon privat/Geschäft

Beste Zeit für einen Anruf

Bitte überprüfen Sie meine Personalversicherungen und senden Sie mir eine Vergleichsofferte. (Bitte legen Sie uns eine Kopie Ihrer aktuellen Versicherungspolicen bei)

Ich wünsche eine persönliche Beratung.

Bitte rufen Sie mich an.

Ich interessiere mich für:

\begin{tabular}{ll} 
Säule 3a & Anlagen mit Kapitalschutz \\
Absicherung der Familie & Rechtsschutzversicherung \\
Krankenkasse & Berufshaftpflichtversicherung \\
\hline
\end{tabular}

\footnotetext{
Anlagen mit Kapitalschutz

Rechtsschutzversicherung

rer
}

O 